\title{
Molecular Pattern of Breast Cancer Among A Series of Egyptian Patients
}

\author{
Salah Elmesidy ${ }^{1}$, Wessam El-sherif ${ }^{1}$, Mohamed Abdelrhman ${ }^{1}$, Waleed Hammam ${ }^{1}$ and \\ Mohamed Abdelshafy ${ }^{2}$.
}

\begin{abstract}
${ }^{1}$ Department of Clinical Oncology and Nuclear Medicine-Kasr Elaini Faculty of Medicine-Cairo University and ${ }^{2}$ Department of Clinical Oncology and Nuclear Medicine- Faculty of Medicine-Bani Swif University.
\end{abstract}

Background: Triple negative (TN) breast cancer has a bad prognosis. It is associated with a poor progressionfree and overall survivals. Accordingly, we explored the outcome of different molecular subtypes among a series of Egyptian breast cancer patients.

Methods: A total of 661 non-metastatic breast cancer patients' files were reviewed from Kasr Al-Aini Center of Clinical Oncology and Nuclear Medicine of Cairo University between January 2005 and December 2010. Data were analyzed for age; menopausal status, tumour size, nodal status, pathological type, grade; estrogen status, progesterone status, and human epidermal growth factor receptor 2 (HER2) status. Disease free survival (DFS) was the primary end point.

Results: The median age was 50 years. $50.4 \%$ of patients were premenopausal, $93.1 \%$ had invasive duct carcinoma, $93.3 \%$ had grade II tumours, $79.4 \%$ had early tumours (T1\&T2), 70.4\% had positive lymph nodes, $51.7 \%$ had luminal A subtype, $21.3 \%$ had luminal B, 10.2\% had Her2-enriched and $16.6 \%$ had TN. Disease free survival after 3 years for each subtype was $87.8 \%$ for luminal A, $86 \%$ for luminal B, $69 \%$ for TN and $66 \%$ for HER2 $(P=.008)$. The 3-year disease-free survival was significantly better for postmenopausal patients 92.1\% as compared with premenopausal patients $80.1 \%(P=<0.001)$, with early tumours (T1\&T2) $92.1 \%$ $\& 87.3 \%$ respectively as compared with advanced tumours (T3+T4) $80.1 \%(P=<0.001)$, LN negative (N0) $98.1 \%$ as compared with $\mathrm{LN}$ positive $(\mathrm{N} 1+\mathrm{N} 2) 85.2 \%$ and $(\mathrm{N} 3) 68 \%(P=<0.001)$, (ER) positive $90.2 \%$ as compared with (ER) negative $78.2 \%(P=<0.001)$, (PR) positive $90 \%$ as compared with (PR) negative $80.2 \%$ $(P=0.003)$, non TNBC $89.8 \%$ as compared with TN $72.1 \%(P=0.012)$. The $2 \& 3$ year disease-free survival for $\mathrm{TN}$ patients $(\mathrm{N}=31)$ who received adjuvant platinum-based chemotherapy was $81 \%$ \& $46 \%$ respectively and for those who received adjuvant non-platinum $(\mathrm{N}=74)$ chemotherapy was $84 \% \& 78 \%$ respectively (log rank $P$-value $=0.135$ ).

Conclusions: In our series of Egyptian patients, luminal breast cancer subtypes (A\& B) had the highest 3-year disease-free survival followed by TN then Her2-enriched type. Adjuvant platinum based chemotherapy had no impact on the 3-year disease-free survival when compared with non-platinum chemotherapy in TN patients.

Key words: breast cancer, egyptian, molecular subtypes, triple negative.

Corresponding Author: Salah Almesidy_Ｅ-mail: salahelmesidy@hotmail.com

\section{INTRODUCTION}

Breast cancer is the most common neoplasm in women, accounting for $26 \%$ of all cancers diagnosed annually, it is overall the second leading cause of cancer death (following lung cancer). In Egypt breast cancer constitutes $33 \%$ of all female cancer and the median age is 46 years old, one decade younger than corresponding western countries. The incidence of breast cancer is highest among women of higher socioeconomic background. Also the incidence is higher among whites less common in black women. Most cancer patients are diagnosed sporadic and not associated with any clear familial predisposition ${ }^{1}$.

Breast cancer is not a single entity but instead comprises several biologically distinct subtypes.
Based on molecular profiles, breast cancers have been classified into four main subtypes: luminal subtype A, luminal subtype B, ERbB2 positive receptors (HER2 positive/ER negative) and $\mathrm{TNBC}^{2,3,4}$.

Triple-negative breast cancer (TNBC) is defined as a clinical entity referring to tumors that do not express estrogen receptor (ER), progesterone receptor (PR), or human epidermal growth factor receptor 2 (HER2) accounting for approximately $15 \%-20 \%$, 0 of breast cancers. TNBC has important clinical implications, because it is typically high grade, and exhibits a high rate of proliferation ${ }^{7,8}$. In general, compared with other subtypes of breast cancer, TNBC has a less favorable clinical outcome in terms of the nature and likelihood of 
progression, availability of various treatment options, and survival ${ }^{9,10}$.

Certain treatment strategies for breast cancer have effectively exploited tumor biology. For examples, hormonal therapies and trastuzumab (Herceptin) target ER and HER2, respectively. TNBC is not amenable to either of these approaches. Although several targeted approaches are currently under investigation in patients with TNBC, the current standard of treatment for these patients consists of cytotoxic therapies such as anthracyclines and taxanes ${ }^{11,12}$.

TNBC has a poorer prognosis than other breast cancer subtypes, regardless of the stage of disease at diagnosis. TNBC is associated with diminished progression- free survival (PFS) and overall survival (OS) after surgery or after recurrence. The risk of distant recurrence within 5 years was significantly higher in patients with TNBC than in those with other subtypes ${ }^{13,14}$.

\section{PATIENTS AND METHODS}

\section{Patient Population:}

This is a retrospective study included 1,103 patients with triple negative \& non TNBC referred to Kasr El-Aini Center of Radiation Oncology and Nuclear Medicine (NEMROCK). Patients' files were reviewed from NEMROCK archive between January 2005 and December 2010. The analysis was performed on a database that was locked on 1st April 2011. during the period between January 2005 and December 2010. Data of all cases (1103) were reviewed regarding clinico-epidemiological features, treatment modalities, progression free and overall survival. we then classified the cases with known all the hormonal profile (ER,PR,HER2) (661) according to their hormonal profile into four groups:-

Luminal A subtype (51.7\%) those with hormonal profile (ER+, PR+, HER2-) and low grade (GI).

Luminal B subtype (21.3\%) those with hormonal profile Luminal B(HER2-) (ER+, PR+ or PR-,HER2-) and Luminal B (HER2+) (ER+, PR+ or PR-,HER2+) with moderate (GII) and high (GIII) grade.

HER2 over expressing subtype (10.2\%) those with hormonal profile(ER-, PR-, HER2+++).

Triple negative subtype (16.6\%) those with hormonal profile (ER-, PR-, HER2-).

In our classification we depend on (the hormonal profile) and (the grade) to classify the luminal subtypes into A \& B subtypes as, the data on the KI $67 \%$ was not available as the test was not routine for the cases during that period from 2005 to 2010 so, it was difficult to use it in the classification of luminal subtypes. The treatment outcome of adjuvant platinum based chemotherapy in TN patients was eventually compared with those of the conventionally treated with adjuvant classic (nonplatinum) chemotherapy.

\section{Inclusion criteria:}

1. Pathologically proven invasive Breast Cancer (TN\& non TN).

2. All age groups:

3. Presentation to NEMROCK from 1st of January 2005 till end of December 2010.

4. ECOG performance status 0-2.

\section{Exclusion criteria:}

1. Patients whom did not receive adjuvant chemotherapy for any reason.

2. Distant metastasis as proved by chest radiograph, isotopic bone scan \& abdominal sonography.

3. Prior chemotherapy or radiotherapy received.

4. Organ dysfunction as proved by (Impaired liver or renal function tests function tests \& abnormal $\mathrm{CBC}$ ) or an Ejection Fraction (EF) less than 50\%].

\section{Treatment Regimens:}

Patients were grouped according to adjuvant treatment received into two groups namely Platinum based chemotherapy and Classic non-platinum chemotherapy e.g. Anthracycline based or taxanes based chemotherapy.

\section{Statistical Analysis:}

The endpoints in this study were disease free survival (DFS). DFS was calculated from the date of start of the primary therapy to the date of breast cancer recurrence, the date of death from any cause, or the date of last follow up. DFS as a function of the markers studied was estimated by the Kaplan-Meier method and the log-rank test was used to test for differences. Data were statistically described in terms of range, mean \pm standard deviation ( \pm SD), frequencies (number of cases) and percentages when appropriate. Survival analysis was done for the different outcome measures using Kaplan Maier statistics calculating the mean and median survival time for each group with their $95 \%$ confidence interval $(95 \% \mathrm{CI})$ and the corresponding survival graphs. Factors examined as a stepwise adjusted Kaplan Meier were age at presentation (missing, $<35,35$ to $49,>50$ years), T status (missing, TX, T1, T2, T3, T4), N status (missing,N0, N1, N2, N3), menopausal status (missing, postmenopausal, premenopausal), ER status (missing, negative, or positive), PR status (missing, negative, or positive), and HER2/neu status (missing, negative, or amplified). A plot of RFS Vs the mentioned factors were calculated and compared between the two groups. A 
Kasr-El-Aini Journal Of Clinical Oncology And Nuclear Medicine

Vol. 9 | No. 1-2 2013

Molecular Pattern of Breast Cancer Among A Series of Egyptian Patients

probability value ( $P$ value) less than 0.05 was considered statistically significant. All statistical calculations were done using computer programs Microsoft Excel 2007 (Microsoft Corporation, NY, USA) and SPSS (Statistical Package for the Social Science; SPSS Inc., Chicago, IL, USA) version 17 for Microsoft Windows.

\section{RESULTS}

\section{Clinico-epidemiological characteristics:}

A total 1,103 breast cancer patients were included in the study between January 2005 and December 2010. Median follow-up time was 27 months. All the files were assessed for the clinico-epidemiological features as shown in table (1). The median age of the patients was 50 years old. $50.4 \%$ were premenopausal, $93.1 \%$ had invasive duct carcinoma, $93.3 \%$ had grade II tumours, $79.4 \%$ had early tumours (T1\&T2), 70.4\% had positive lymph nodes, 51.7\% had luminal A subtype, $21.3 \%$ had luminal B, $10.2 \%$ had Her2-enriched and $16.6 \%$ had TN. The cases with known all the hormonal profile [ER,PR,HER2] were 661 patients represented $60 \%$ of the total breast cancer patients. these group of patients subdivided according to their hormonal profile and grade into four subtypes [Luminal A] $=342$ patients $(51.7 \%)$, [Luminal B] = 141 patients $(21.3 \%)$, [HER 2 over expressed] $=68$ patients $(10.2 \%)$ and [Triple negative patients] $=110$ patients $(16.6 \%)$.

\section{The 3-year disease-free survival:}

The 3-year disease-free survivals of all cases (1103) were assessed in relation to the clinico-epidemiological features as shown in table (2) and it was significantly better for postmenopausal patients $92.1 \%$ as compared with premenopausal patients $80.1 \%(P=<0.001)$, with early tumours (T1\&T2) 92.1\% \& 87.3\% respectively as compared with advanced tumours (T3+T4) $80.1 \%$ $(P=<0.001$ ), LN negative (N0) $98.1 \%$ as compared with $\mathrm{LN}$ positive $(\mathrm{N} 1+\mathrm{N} 2) \quad 85.2 \%$ and $(\mathrm{N} 3) \quad 68 \%$ $(P=<0.001)$, (ER) positive $90.2 \%$ as compared with (ER) negative $78.2 \%(P=<0.001)$, (PR) positive $90 \%$ as compared with (PR) negative $80.2 \%(P=0.003)$, non TNBC $89.8 \%$ as compared with TN $72.1 \%(P=0.012)$ Fig. 1 .

The 3-year disease-free survivals of the four subtypes were assessed in relation to the clinico-epidemiological features as shown in Table (3). Disease free survival after 3 years for each subtype was $87.8 \%$ for luminal A, $86 \%$ for luminal B, 69\% for TN and 66\% for HER2 $(P=.008)$ Fig. 2.

The $2 \& 3$ year disease-free survival for TN patients $(\mathrm{N}=31)$ who received adjuvant platinumbased chemotherapy was $81 \%$ \& $46 \%$ respectively and for those who received adjuvant non-platinum $(\mathrm{N}=74)$ chemotherapy was $84 \%$ \& $78 \%$ respectively (log rank $P$-value $=0.135)$ as shown in Fig. 3.

Table 1: Clinico-epidemiological characteristics of all breast cancer

\begin{tabular}{lcc}
\hline Characteristics & number & percent $\%$ \\
\hline Age (median, range) & 50 & \\
\hline Age groups & & \\
\hline Valid $<35$ & 87 & 7.9 \\
\hline $35-50$ & 507 & 46.0 \\
\hline$>50$ & 509 & 46.1 \\
\hline Total & 1103 & 100 \\
\hline
\end{tabular}

\begin{tabular}{lcc}
\hline Menopausal status & & \\
\hline premenopausa & 546 & 50.4 \\
\hline postmenopausal & 538 & 49.6 \\
\hline Total & 1084 & 100 \\
\hline unknown & 19 & \\
\hline Total & 1103 & \\
\hline Tumour type & & 93.1 \\
\hline invasive ductal & 1026 & 4.4 \\
\hline invasive lobular & 49 & 0.9 \\
\hline Mixed & 10 & 1.6 \\
\hline Missing & 18 & 100 \\
\hline Total & 1103 & \\
\hline T- stage & & 17.8 \\
\hline valid 1 & 186 & 61.6 \\
\hline 2 & 643 & 5.4 \\
\hline 3 & 56 & 15.1 \\
\hline 4 & 158 & 100 \\
\hline Total & 1043 & \\
\hline Missing & 60 & \\
\hline Total & 1103 & 2906 \\
\hline $\mathbf{N}-$ stage & & 26.7 \\
\hline valid 0 & 326 & 25.3 \\
\hline 1 & 295 & 18.4 \\
\hline 2 & 279 & 100 \\
\hline 3 & 203 & \\
\hline Total & 1103 & \\
\hline Grade & & \\
\hline
\end{tabular}

Grade

\begin{tabular}{lcc}
\hline valid I & 4 & 0.4 \\
\hline II & 1013 & 93.3 \\
\hline III & 69 & 5.3 \\
\hline
\end{tabular}

\begin{tabular}{ll} 
III & 69 \\
\hline Missing & 17 \\
\hline
\end{tabular}

\begin{tabular}{lc} 
Missing & 17 \\
\hline Total & 1103 \\
\hline
\end{tabular}

\begin{tabular}{lcc}
\hline ER- status & & \\
\hline valid positive & 776 & 70.6 \\
\hline negative & 323 & 29.4 \\
\hline total & 1099 & \\
\hline PR- status & & 32.0 \\
\hline valid positive & 746 & 68.0 \\
\hline negative & 351 & 100 \\
\hline total & 1097 & \\
\hline missing & 6 & \\
\hline Total & 1103 & \\
\hline HER- status & & 31.6 \\
\hline valid positive & 209 & 68.4 \\
\hline negative & 452 & 100 \\
\hline tota & 661 & \\
\hline missing & 442 & \\
\hline Total & 1103 & \\
\hline Hormonal profile & & 51.7 \\
\hline valid luminal A & 342 & 21.3 \\
\hline luminal B & 141 & 10.2 \\
\hline HER2 over expressed & 68 & 16.6 \\
\hline TN & 110 & 100 \\
\hline Total & 661 & \\
\hline Unknown HER2 & 442 & \\
\hline Total & 1103 & \\
\hline & & \\
\hline & & \\
\hline
\end{tabular}


Table 2: the 3 years disease free survival in relation to clinico-epidemiological characteristics of all breast cancer cases (1103) and their statistical significance.

\begin{tabular}{|c|c|c|c|c|}
\hline Measurement & & Number of cases & 3 years DFS (\%) & $\begin{array}{l}\text { P-value* } \\
\text { (log rank) }\end{array}$ \\
\hline Total & & 1103 & 88.8 & \\
\hline \multirow[t]{3}{*}{ Age } & $<35$ & 87 & 67.5 & \\
\hline & $35-50$ & 507 & 90.1 & \\
\hline & $>50$ & 509 & 87.7 & $<0.001$ \\
\hline \multirow[t]{2}{*}{ Menopause } & Pre. & 546 & 80.1 & \\
\hline & Post. & 538 & 92.1 & $<0.001$ \\
\hline \multirow[t]{3}{*}{$\mathrm{T}$ stage grouped } & 1 & 186 & 92.1 & \\
\hline & 2 & 643 & 87.3 & \\
\hline & $3-4$ & 214 & 80.1 & $<0.001$ \\
\hline \multirow[t]{3}{*}{ N Stage grouped } & None & 326 & 98.1 & \\
\hline & $1-2$ & 574 & 85.2 & \\
\hline & 3 & 203 & 68.0 & $<0.001$ \\
\hline \multirow[t]{2}{*}{ ER } & Positive & 776 & 90.2 & \\
\hline & Negative & 323 & 78.2 & $<0.001$ \\
\hline \multirow[t]{2}{*}{ PR } & Positive & 746 & 90.0 & \\
\hline & Negative & 351 & 80.2 & 0.003 \\
\hline \multirow[t]{2}{*}{ HER 2} & Positive & 209 & 75.2 & \\
\hline & Negative & 452 & 89.0 & 0.219 \\
\hline \multirow[t]{2}{*}{ Biology } & NTN & 551 & 89.8 & \\
\hline & $\mathrm{TN}$ & 110 & 72.1 & 0.012 \\
\hline
\end{tabular}

$*$ P-value $\leq 0.05$ is considered significant.

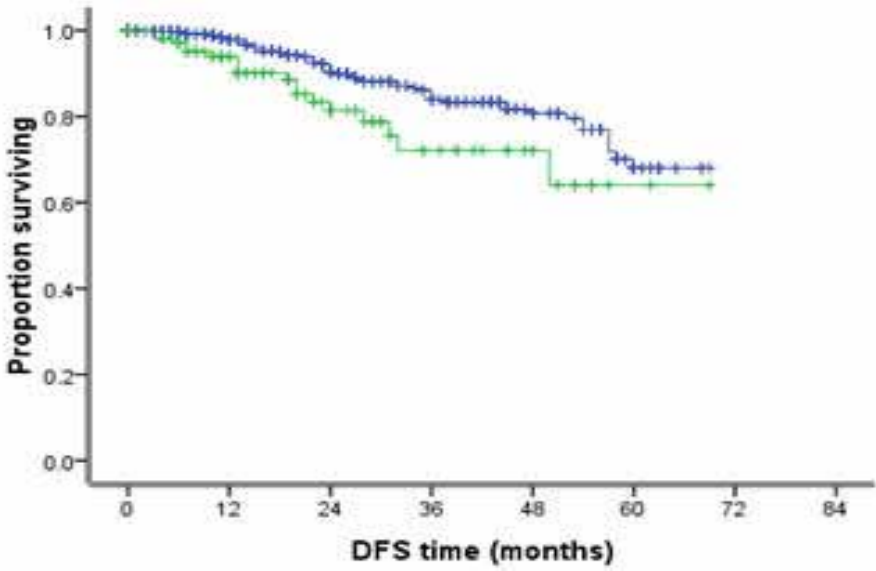

Fig. 1: Kaplan Meier survival curve of DFS of TN and NTN with statistical significance $(P$ - value $=0.012)$. 
Kasr-El-Aini Journal Of Clinical Oncology And Nuclear Medicine

Vol. 9 | No. 1-2 2013

Molecular Pattern of Breast Cancer Among A Series of Egyptian Patients

Table 3: The 3 years disease free survival in relation to clinico-epidemiological characteristics of the four subtypes and their statistical significance.

\begin{tabular}{|c|c|c|c|c|c|c|c|c|c|}
\hline & \multicolumn{2}{|c|}{ Luminal A } & \multicolumn{2}{|c|}{ Luminal B } & \multicolumn{2}{|c|}{ TN } & \multicolumn{2}{|c|}{ HER2 } & \multirow[b]{2}{*}{$P$-value } \\
\hline & No. & DFS \% & No. & DFS\% & No. & DFS \% & No. & DFS\% & \\
\hline DFS\%: & 342 & $87.8 \%$ & 141 & $86.0 \%$ & 110 & $69 \%$ & 68 & $66.0 \%$ & 0.008 \\
\hline $\begin{array}{l}\text { AGE: } \\
\leq 50 \\
>50\end{array}$ & $\begin{array}{l}169 \\
173\end{array}$ & $\begin{array}{c}88 \% \\
87.2 \%\end{array}$ & $\begin{array}{l}79 \\
62\end{array}$ & $\begin{array}{l}84.7 \% \\
89.4 \%\end{array}$ & $\begin{array}{l}56 \\
54\end{array}$ & $\begin{array}{l}68.0 \% \\
70.0 \%\end{array}$ & $\begin{array}{l}44 \\
24\end{array}$ & $\begin{array}{l}67.7 \% \\
34.1 \%\end{array}$ & $\begin{array}{c}0.071 \\
<0.001\end{array}$ \\
\hline $\begin{array}{l}\text { Menopausal } \\
\text { Status: } \\
\text { Pre. } \\
\text { Post. } \\
\end{array}$ & $\begin{array}{l}150 \\
192 \\
\end{array}$ & $\begin{array}{l}86.0 \% \\
88.9 \% \\
\end{array}$ & $\begin{array}{l}80 \\
61 \\
\end{array}$ & $\begin{array}{l}74.1 \% \\
91.2 \% \\
\end{array}$ & $\begin{array}{l}47 \\
63 \\
\end{array}$ & $\begin{array}{l}68.1 \% \\
73.3 \% \\
\end{array}$ & $\begin{array}{l}44 \\
24\end{array}$ & $\begin{array}{l}65.9 \% \\
100 \% \\
\end{array}$ & $\begin{array}{l}0.062 \\
0.002 \\
\end{array}$ \\
\hline $\begin{array}{l}\text { T-stage: } \\
\text { Early1+2 } \\
\text { Advanced3+4 }\end{array}$ & $\begin{array}{c}281 \\
61 \\
\end{array}$ & $\begin{array}{c}90.6 \% \\
75 \% \\
\end{array}$ & $\begin{array}{c}113 \\
28 \\
\end{array}$ & $\begin{array}{l}89.5 \% \\
74.3 \% \\
\end{array}$ & $\begin{array}{l}86 \\
23 \\
\end{array}$ & $\begin{array}{l}75.4 \% \\
66.7 \% \\
\end{array}$ & $\begin{array}{l}52 \\
16 \\
\end{array}$ & $\begin{array}{l}72.5 \% \\
62.4 \% \\
\end{array}$ & $\begin{array}{l}0.071 \\
0.081 \\
\end{array}$ \\
\hline $\begin{array}{l}\text { N-stage: } \\
\text { positive } \\
\text { negative }\end{array}$ & $\begin{array}{l}229 \\
113\end{array}$ & $\begin{array}{l}85.6 \% \\
93.1 \%\end{array}$ & $\begin{array}{l}90 \\
51\end{array}$ & $\begin{array}{l}84.3 \% \\
92.4 \%\end{array}$ & $\begin{array}{l}79 \\
31\end{array}$ & $\begin{array}{l}67.3 \% \\
88.8 \%\end{array}$ & $\begin{array}{l}46 \\
22\end{array}$ & $\begin{array}{l}50.6 \% \\
100 \%\end{array}$ & $\begin{array}{l}0.005 \\
0.251\end{array}$ \\
\hline
\end{tabular}

*P-value $\leq 0.05$ is considered significant.

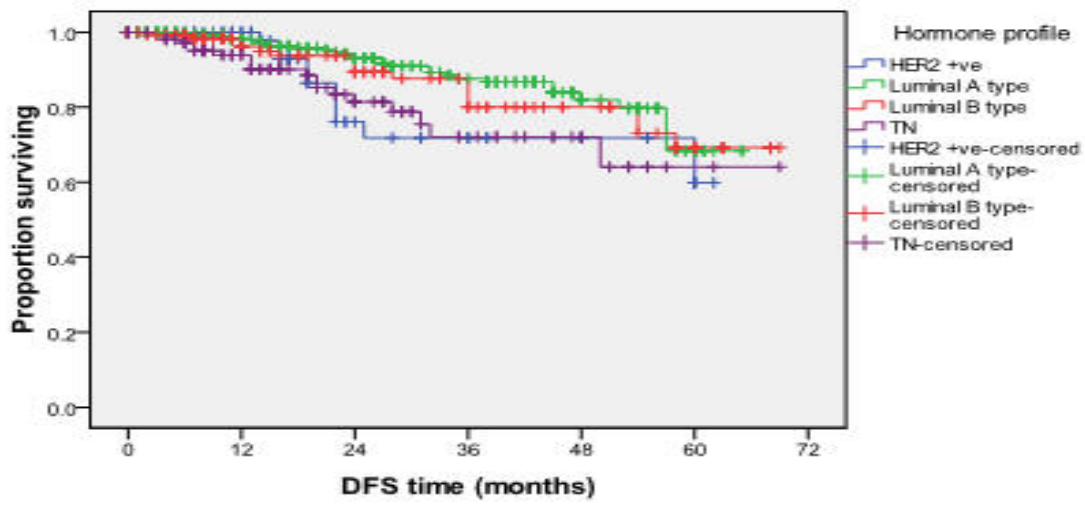

Fig. 2: Kaplan Meier survival curve of DFS of all hormonal profile with statistical significance $(P$ - value $=0.008)$.

Table 4: 3 years disease free survival of TN patients in relation to clinicoepidmiological features.

\begin{tabular}{lccc}
\hline Measurement & Number of cases & 3 years DFS (\%) & $\boldsymbol{P}$-value*(Log -rank) \\
\hline Age & & & \\
\hline$<=50$ years & 56 & $68.0 \%$ & 0.132 \\
\hline$>50$ years & 54 & $70.0 \%$ & \\
\hline Menopause & & & 0.285 \\
\hline Pre & 47 & $73.3 \%$ & \\
\hline Post & 63 & & 0.610 \\
\hline T-stage & & $75.4 \%$ & \\
\hline Early (1+2) & 86 & $66.7 \%$ & \\
\hline Advan. (3+4) & 23 & & \\
\hline N Stage & & $88.8 \%$ & $<0.001$ \\
\hline N0 & 31 & $80.7 \%$ & \\
\hline N1-2 & 55 & $34.6 \%$ & \\
\hline N3 & 24 & & \\
\hline Adjuvant & & $46.0 \%$ & \\
\hline Platinum & 31 & $78.0 \%$ & \\
\hline Classic & 74 & & \\
\hline
\end{tabular}

* P-value $\leq 0.05$ is considered significant. 


Vol. 9|No. 1-2 $2013 \quad$ Salah Elmesidy et al.

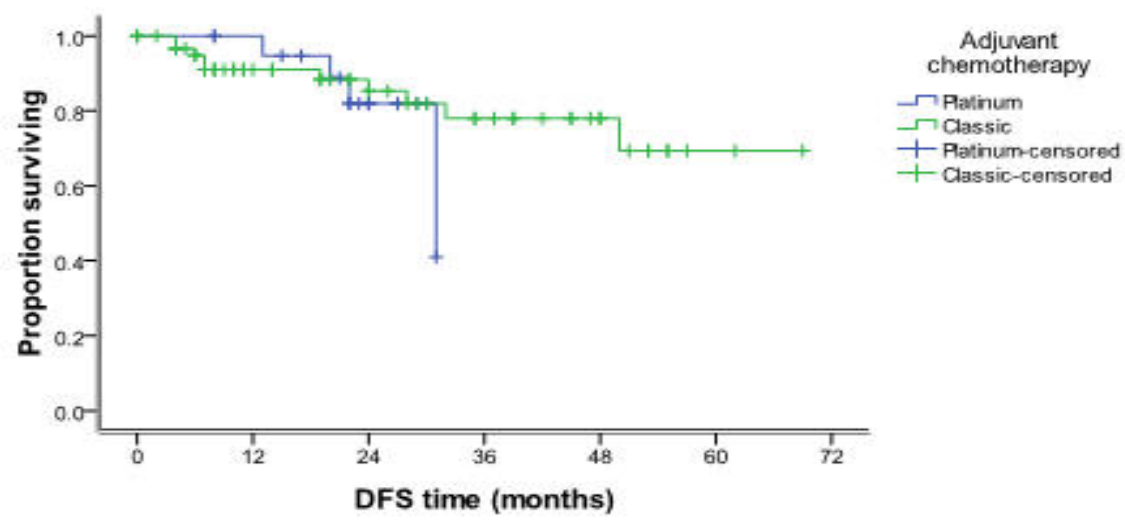

Fig. 3: Kaplan Meier survival curve of DFS of the two adjuvant treatment arms with statistical significance $(P$ - value $=0.13)$.

\section{DISCUSSION}

In this study, breast cancer represented $31.4 \%$ of total number of cancer cases presented to Kasr elaini centre of clinical oncology and nuclear medicine (NEMROCK) between 1st of January 2005 and 31th December 2010. That percentage is more than the percentage proved by one of our national retrospective studies done by Yasser et al. ${ }^{15}$ in the period between 1997 and 1999 in NEMROCK as well as the international results ${ }^{16}$. This increase in the incidence in our study is due to the increase in the number of referred breast cancer cases to NEMROCK from other centers to receive radiotherapy either (palliative or adjuvant) and also to have a second opinion.

On comparing the results of tumour sizes at presentation for patients presented to NEMROCK in the current study with the study done by Yasser et $a l .{ }^{15}$, it was observed that an increase in the early detected tumours T1 and T2 with decrease in the incidence of advanced detected tumours T3 and T4 which mostly due the increase in the awareness of Egyptian females by screening programs with the development and spread of that programs which enables early detection of breast cancer at its early stages.

In the whole studied group, it was observed that lymph node involvement was almost equally divided among the three nodal states (N0,N1 and N2) $)^{15}$. These results showed that almost two thirds of the patients are considered to be at high risk groups that lead to poorer outcome $\mathrm{e}^{17,18}$.

On studying the effect of hormonal receptor status we found that ER positive patients experienced higher DFS percentage that represents $90.2 \%$ when compared with ER negative patients $78.2 \%$, also PR positive patients have higher 3 years DFS $90.0 \%$ when compared with PR negative patients $80.2 \%$. That results are in agree with the results proved in the study done by (Dunnwald et $a l .{ }^{19}$ who compared patients with $\mathrm{ER}+/ \mathrm{PR}+$ with other group of patients with different hormonal profiles $\{$ ER+/PR-, ER-/PR+, or ER-/PR- $\}$ and it achieved the best DFS and the last group of tumors $\{\mathrm{ER}-/ \mathrm{PR}-\}$ experienced higher risks of mortality and low DFS.

On studying the effect of HER 2 status on 3 years DFS, we detected that HER2 negative cases showed 3 years DFS $89.0 \%$ better than HER 2 positive cases that showed 3 years DFS $75.2 \%$ but, with no statistical significance $P=0.21$. That results are in agree with results of study done in Queen Elizabeth hospital by Tovey et al. ${ }^{20}$ who detected that HER2 positive patients had 3-year breast cancer-specific survival rates of $68 \%$ compared with $96 \%$ for the HER2-negative group. This result is attributed to the aggressiveness of HER2 positive tumours when compared with HER2 negative tumours. Also HER2 positive cases didn't receive [trastuzumab].

Comparing the 3 years DFS for all group of non TNBC and TNBC we detected a survival difference between both groups with better survival for non TNBC with $P$ value $=0.012$. That results are comparable with the results in the study done by Dent et al. ${ }^{13}$ who proved that TNBC patients had an increased like hood of distant recurrence (33.9\% for TN versus $20.4 \%$ for non TNBC) and death within 5 years of diagnosis.

We compared the 3 years DFS of the four groups and we found that HER2 over expressing followed by TNBC patients experienced the worst 3 years DFS than luminal subtypes represented $66.0 \%$ and $69.0 \%$, respectively ${ }^{6}$. The explanation for that is due to the lack of the gene expression profiling to identify basal subtype markers $\{\mathrm{Ck} 5 / 6$, and epidermal growth factor receptor (EGFR) $\}$ to help us to differentiate the TNBC group into basal of (bad prognosis) and non basal of (good prognosis) subtypes. Also HER2 positive cases didn't receive trastuzumab. 
We divided the TN patients in two arms. Arm I, patients received platinum based chemotherapy as an adjuvant treatment and they were 31 patients and arm II, patients received other non platinum classic chemotherapy as an adjuvant treatment and they were 74 patients. The DFS curves for both arms were close at 48 months ( $81 \%$ for arm I and $84 \%$ for arm II), however at 30 months the difference became very large being $46 \%$ for arm I and $78 \%$ for arm II and in spite of large numerical difference after 30 months there was no significance between both curves (log rank $P$-value $=0.135)$. This may be due the small difference till at least 24 months, the small sample size especially in arm I and short follow up period.

\section{CONCLUSION}

HER2 over expressing followed by TNBC patients experienced the worst 3 years DFS than luminal subtypes. No survival difference is detected between patients who received platinum based chemotherapy and other patients who received classical non-platinum chemotherapy protocol.

\section{REFERENCES}

1. EL-BOKAINY. Topographic pathology of cancer. 1998.

2. Morris GJ, Naidu S, Topham AK, Guiles F, Xu Y, McCue $\mathrm{P}$, et al. Differences in breast carcinoma characteristics in newly diagnosed African-American and Caucasian patients: A single-institution compilation compared with the National Cancer Institute's Surveillance, Epidemiology and End Results database. Cancer 2007;110(4):876-84.

3. Perou CM, Sørlie T, Eisen MB, van de Rijn M, Jeffrey SS, Rees CA, et al. Molecular portraits of human breast tumours. Nature 2000;406(6797):747-52.

4. Hu Z, Fan C, Oh DS, Marron JS, He X, Qaqish BF, et al. The molecular portraits of breast tumors are conserved across microarray platforms. BMC Genomics 2006;7:96.

5. Haffty BG, Yang Q, Reiss M, Kearney T, Higgins SA, Weidhaas $\mathrm{J}$, et al. Locoregional relapse and distant metastasis in conservatively managed triple negative earlystage breast cancer. J.Clin.Oncol. 2006;24(36):5652-7.

6. Kwan ML, Kushi LH, Weltzien E, Maring B, Kutner SE, Fulton RS, et al. Epidemiology of breast cancer subtypes in two prospective cohort studies of breast cancer survivors. Breast Cancer Res. 2009;11(3):R31.

7. Anders CK, Carey LA. Biology, metastatic patterns and treatment of patients with triple-negative breast cancer. Clin.Breast Cancer 2009;9(Suppl. 2):S73-81.
8. Cleator S, Heller W, Coombes RC. Triple-negative breast cancer: Therapeutic options. Lancet Oncol. 2007;8(3):235-44.

9. Carey LA, Perou CM, Livasy CA, Dressler LG, Cowan D, Conway K, et al. Race, breast cancer subtypes and survival in the Carolina Breast Cancer Study. J.Am. Med.Assoc. 2006;295(21):2492-502.

10. Bauer KR, Brown M, Cress RD, Parise CA, Caggiano V. Descriptive analysis of estrogen receptor (ER)-negative, progesterone receptor (PR)-negative, and HER2-negative invasive breast cancer, the socalled triple-negative phenotype: A population-based study from the California cancer Registry. Cancer 2007;109(9):1721-8.

11. Liedtke C, Mazouni C, Hess KR, André F, Tordai A, Mejia JA, et al. Response to neoadjuvant therapy and long-term survival in patients with triple-negative breast cancer. J.Clin.Oncol. 2008;26(8):1275-81.

12. Rakha EA, Reis-Filho JS, Ellis IO. Basal-Like Breast Cancer: A Critical Review. J.Clin.Oncol. 2008;26(2568):2581.

13. Dent R, Trudeau M, Pritchard KI, Hanna WM, Kahn HK, Sawka CA, et al. Triple-negative breast cancer: Clinical features and patterns of recurrence. Clin.Cancer Res. 2007;13(15 pt 1):4429-34.

14. Dent R, Hanna WM, Trudeau M, Rawlinson E, Sun P, Narod SA. Pattern of metastatic spread in triplenegative breast cancer. Breast Cancer Res.Treat. 2009; 115(2):423-8.

15. Yasser A, Elfarouk O, Elmetnawy W, Haggag M. A retrospective study about clinicobiological features of female breast cancer from the period 1997 to 1999. 2001.

16. Parker JS, Mullins M, Cheang MC, Leung S, Voduc D, Vickery T, et al. Supervised risk predictor of breast cancer based on intrinsic subtypes. J.Clin.Oncol 2009; 27(8):1160-7.

17. Tian XS, Cong MH, Zhou WH, Zhu J, Chen YZ, Liu Q. Clinicopathologic and prognostic characteristics of triplenegative breast cancer. Onkologie 2008;31(11):610-4.

18. Gluz O, Liedtke C, Gottschalk N, Pustzai L, Nitz U, Harbeck N. Triple-negative breast cancer-current status and future directions. Ann.Oncol. 2009;20(12):1913-27.

19. Dunnwald LK, Rossing MA, Li CI. Hormone receptor status, tumor characteristics and prognosis: A prospective cohort of breast cancer patients. Breast Cancer Res. 2007;9(1):R6.

20. Tovey SM, Brown S, Doughty JC, Mallon EA, Cooke TG, Edwards J. Poor survival outcomes in HER2positive breast cancer patients with low-grade, nodenegative tumours. Br.J.Cancer 2009;100(5):680-3. 